\title{
Minimal Detectable Displacement Achievable by GPS-RTK in CZEPOS Network
}

\author{
Martin Raška a and Jiří Pospíšil ${ }^{\mathrm{b}}$ \\ ${ }^{a}$ Katastrální úřad pro Karlovarský kraj, Katastrální pracoviště Sokolov \\ Boženy Němcové 1932, 35601 Sokolov, Czech Republic \\ martin.raska@cuzk.cz \\ ${ }^{\mathrm{b}}$ Faculty of Civil Engineering, Department of Special Geodesy \\ Thákurova 7, Praha 6 16629, Czech Republic \\ pospisil@fsv.cvut.cz
}

\begin{abstract}
In this paper we have made a brief study of RTK precision to estimate possibilities of network RTK using CZEPOS for purposes of geotechnic monitoring of landslides in real time. In this paper we describe a testing methodology, which resulted in estimation of point-position precision and describing minimal detectable positional change. Based on our results it is concluded that displacements could be detected with centimetre accuracy even with short-period observations.
\end{abstract}

Keywords: GNSS, network RTK, landslide monitoring

\section{Introduction}

The measurements with GNSS are easier than terrestrial methods for displacement monitoring of points [12]. As GNSS technology and short observation time, followed up by terrestrial observation, usually provides sufficient precision for rough position precision requirements, as shown in experimental geomorphologic analysis [9], with increasing demands on precision, usually terrestrial methods are preferred, despite their complicated and time consuming procedure [1]. Unlike to RTK, the position of observed points with permanent stations may by determined with millimetre accuracy [6].

In 2007, 27 permanent GPS reference stations comprised the CZEPOS reference system. They cover almost the whole area of the Czech Republic, however some border areas extend outside this network (see Fig. 1), 23 of them owned and maintained by the Land Survey Office, whilst the others are supported and maintained by research facilities. At the end of 2008, the whole network had been connected with surrounding networks in Germany, Austria, Poland and Slovakia, thus computing corrections in border areas of the Czech Republic has become more reliable. In December 2009, reference station in Moravský Krumlov has been relocated to Znojmo. Besides storing continuous data for post-processing computing (available through the web pages of the Land Survey Office [5]), real-time data are provided as well. Data flow could be divided into two parts - DGPS corrections (code only, for GIS applications, decimetre precision) and RTK phase based corrections (centimetre precision). In this paper only the RTK service will be discussed.

Geoinformatics FCE CTU 14(1), 2015, doi:10.14311/gi.14.1.2 


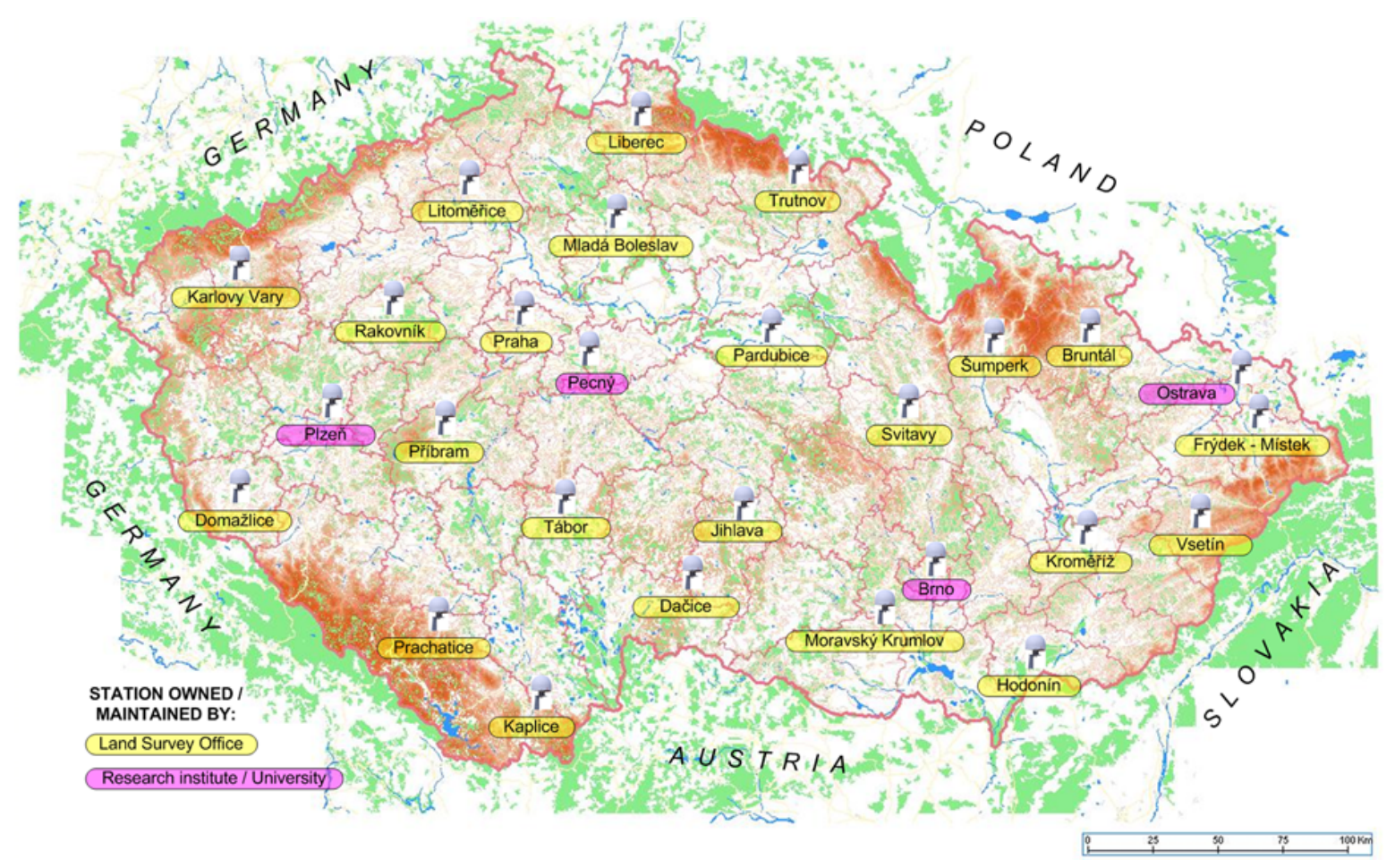

Figure 1: Reference stations of CZEPOS network

Basically, three different kinds of position solution are provided: Simple RTK, RTK-FKP and RTK-PRS. In "Simple RTK" the user chooses one of the reference stations, and corrections are then computed from that reference station only. This method is the least precise, as accuracy of baseline vector determination decreases with increasing length, as shown in [2]. Method is used only with very short baseline vector lengths or under some special circumstances (the next two solutions are computed as network solutions thus during a network solution failure, only "simple" corrections from individual reference stations are available). In "RTK - FKP", the nearest reference station is chosen automatically, but corrections are computed from modelling of the whole network area (data from all CZEPOS stations are processed). The last service provided is "RTK - PRS". In fact, PRS (pseudo-reference station) is the other name for virtual reference station (VRS), where the user gets corrections and/or observables from a virtual reference station [2], based on his initial position (NMEA) provided by a GNSS rover. Observables are computed for the reference station virtually located approximately $5 \mathrm{~km}$ from rover position, in the direction to the nearest reference station. Observables are created from network model of corrections, taking all observations in the whole network into account. Several experiments [10] proved that the precision of a VRS position is similar (thus being in order of $10^{-2} \mathrm{~m}$ ) to those achieved by Simple RTK.

Corrections are received by a GPRS modem, usually integrated in a GNSS receiver, but today only the GPRS protocol is being used, while the whole area of the Czech Republic is covered by GSM signals and the GPRS data rate (theoretically with maximum at hundreds of kbps, [13]) meets the requirements for on-line data processing.

As common in such applications, the international standard Radio Technical Commission for 
Maritime Services (RTCM) version 2.3 is currently used. In February 2009 the Land Survey Office introduced improved version of RTCM (version 3.1), which supports GLONASS correction transfer and has a more effective structure. With the last version of RTCM message [15], a new service "VRS3-MAX" became operational. With this service, observables and corrections for a virtual reference station are computed from a few (usually six) reference stations surrounding the rover. The closest one (called "Master") provides correction data and the others (called "Auxiliary") provide correction differences. There is an alternative service "VRS3-iMAX" for older types of receivers, where the user receives only correction data from the Master station, but Auxiliary stations data are already included in computation. Messages with corrections are sent via Networked Transport of RTCM via Internet Protocol (NTRIP) as needed for data transfer using Internet (as described in [15] and [14]).

\section{Background theory}

\section{Coordinate system in the Czech Republic}

For land surveying purposes, the Czech Republic uses its own national coordinate system (abr. S-JTSK). It could be described as two axes perpendicular to each other, axis $+Y$ heading to west, axis $+\mathrm{X}$ heading to south. The origin is chosen so that the $\mathrm{X}$-coordinate value is always greater than the $\mathrm{Y}$-coordinate value, with horizontal angles measured in a clockwise direction. The height coordinate system (abr. Bpv), is a combination of levelling and gravity observations, which are used to derive heights (according to Molodensky's theory $[7])$.

The European continent drifts approximately $2-3 \mathrm{~cm} /$ year so the CZEPOS system primarily works with European Terrestrial Reference System (ETRS-89) instead of WGS84. Thus 3D-transformation from ETRS89 to S-JTSK (and Bpv) is required and is discussed below.

\section{Datum transformation}

Different solutions for transforming ETRS89 coordinates to the national system S-JTSK using universal transformation parameters already exist. The one used in Trimble GPS devices proved unusable in real applications due to distortion of the S-JTSK. This leads to very large residual vectors between "computed" (using global transformation) and "known" (computed from terrestrial observations) coordinates of points. Thus a local transformation is commonly being used. The experiment described below used a local transformation with 5 identical points (points with known coordinates in both the ETRS89 and S-JTSK system). In June 2008, Trimble introduced an improved global transformation algorithm, based on prof. Kostelecky's work [3]. Despite having a "random" characteristic of residual vector headings (compared with the original Trimble transformation), results (computed for the area surrounding city of Karlovy Vary) are better in scale by approximately one order (as we can see at Fig. 2).

The coordinates of all identical points used for a transformation, both ETRS89 and S-JTSK obtained from the Land Survey Office Database, have been used. As horizontal and vertical coordinates in national systems come from two different sources of observations and computations, local transformation from ETRS89 to S-JTSK (and Bpv) are strongly recommended to be separated into two standalone parts, horizontal and vertical (practical applications showed that using a geoid model for vertical transformation proved useful, while the geoid model 


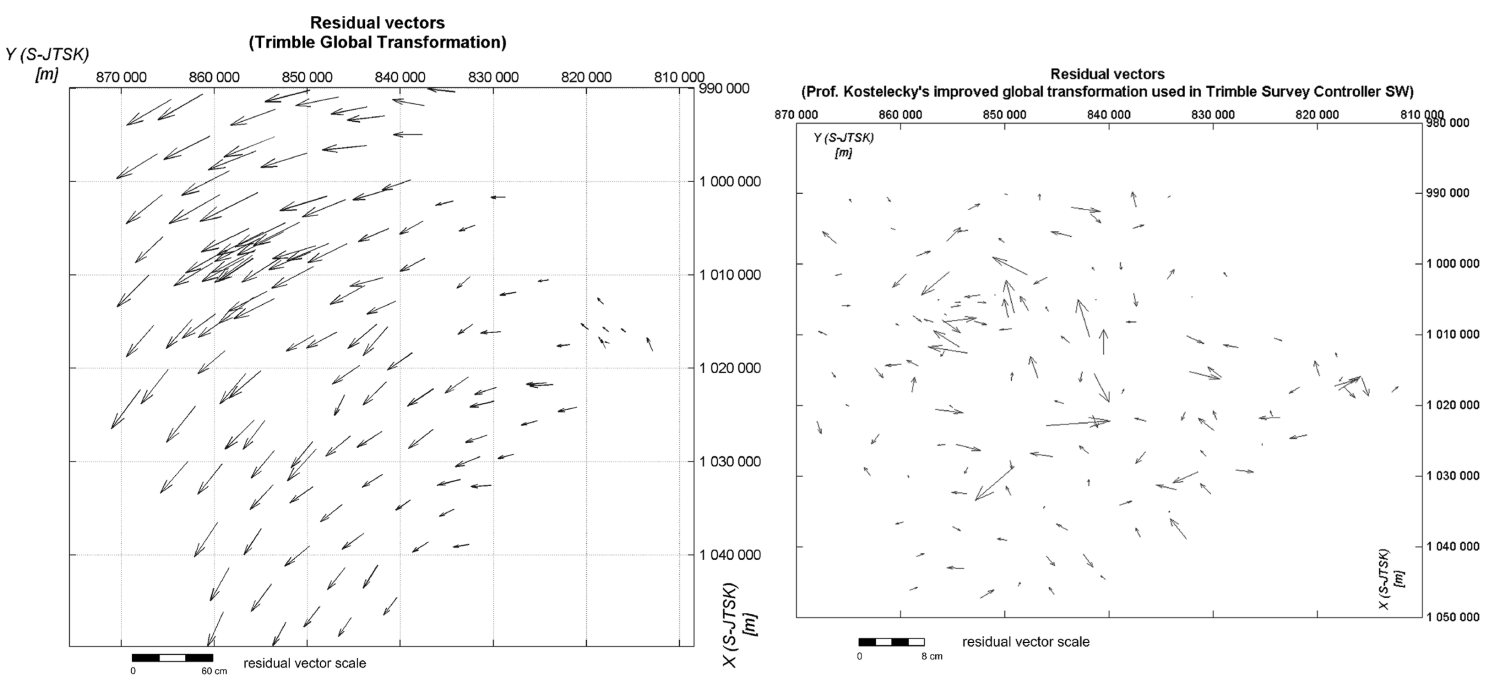

Figure 2: Comparing residual vectors of global transformation

for the Czech Republic [4] gives better results than generally used EGM96). Announced in October 2010, reference frame of the ETRS (ETRF89) is replaced by the ETRF2000.

\section{Experiment overview}

We chose three different sites A-C (with different terrain morphology), see Fig. 3 (represented by surveying landmark - granite stones with a diagonal cross on their top), located inside the area defined by identical-points to be used for the datum transformation. Each observation at one site included three kinds of CZEPOS data receiving (RTK only, RTK-FKP or RTKPRS), each one for three different observation lengths (default options of receiver) periods $(1 \mathrm{~s}, 5 \mathrm{~s}$ and approximately $180 \mathrm{~s}$ ). For statistical analysis of the data we stored S-JTSK coordinates, as well as a priori accuracy characteristics. In the next step we used the entire data record for an empiric estimation of precision. During the experiment the only device used was a GPS rover Trimble R8.

\section{Precision estimation}

As the aim of this experiment was to describe the possibilities of RTK for point position change, there was no interest in deriving absolute positional accuracy in S-JTSK. Only the precision of repeatedly observed point has been tested.

As mentioned earlier, the whole data set was used for computation of positional precision estimation. During the testing procedure in three different areas (with different terrain morphology), possible systematic error (caused by specific environmental conditions) was significantly reduced. After obtaining a set of coordinates, adjustment using the least square method was used. In fact, it led to a computation of the weighted mean value for each coordinate (it was impossible to process all coordinates at one go due to their correlation; three coordinates - Y, X, H from each observation are correlated as being computed from the same set of pseudoranges).

We solved (or at least reduced) problems with different satellite constellations by introducing 


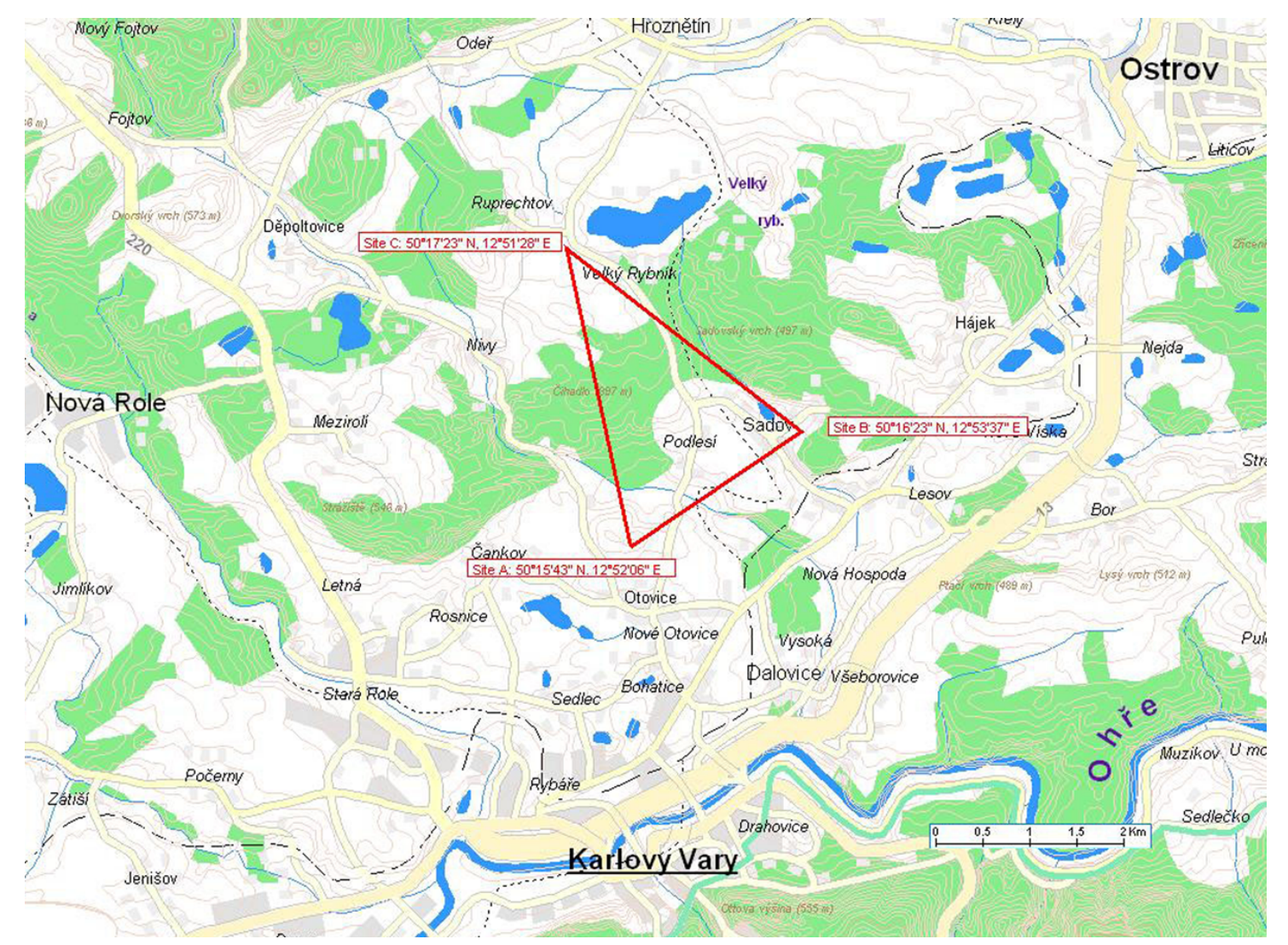

Figure 3: Geometric configuration of sites occupied during experiment

a Relative Dilution of Precision (RDOP) value for the deriving weights, as it takes into account satellite-receiver(s) geometric configuration as well as its changes during observation and observation interval [16]. Progress of RDOP value (based on model using testing site A, reference station in Karlovy Vary and 4 visible satellites) is shown at Fig. 4 . It is clear, that unlike PDOP, RDOP value depends not only on instant satellite configuration, but on configuration-change during observation and observation length as well.

The next input parameter used to derive weights was the root mean square (RMS), computed during the observation. The RMS indicates the quality of the (ambiguity) solution based solely on the measurement noise of the satellite ranging observations. Using this value helped us to implement several random and systematic errors, such as multipath.

As we could derive horizontal and vertical interpretations of RDOP (called HDOP and VDOP $[2]$ ), weights for observation $i$ can be expressed as:

$$
\begin{aligned}
& p_{X, i}=p_{Y, i}=\frac{2}{R M S_{i}^{2} H D O P_{i}^{2}} \\
& p_{H, i}=\frac{1}{R M S_{i}^{2} \operatorname{VDOP}_{i}^{2}}
\end{aligned}
$$

The next step has led to computation of residuals $v$, using a weighted average, and deriving a value of the "general" standard deviation (for $n^{\prime}$ as number of degrees of freedom): 


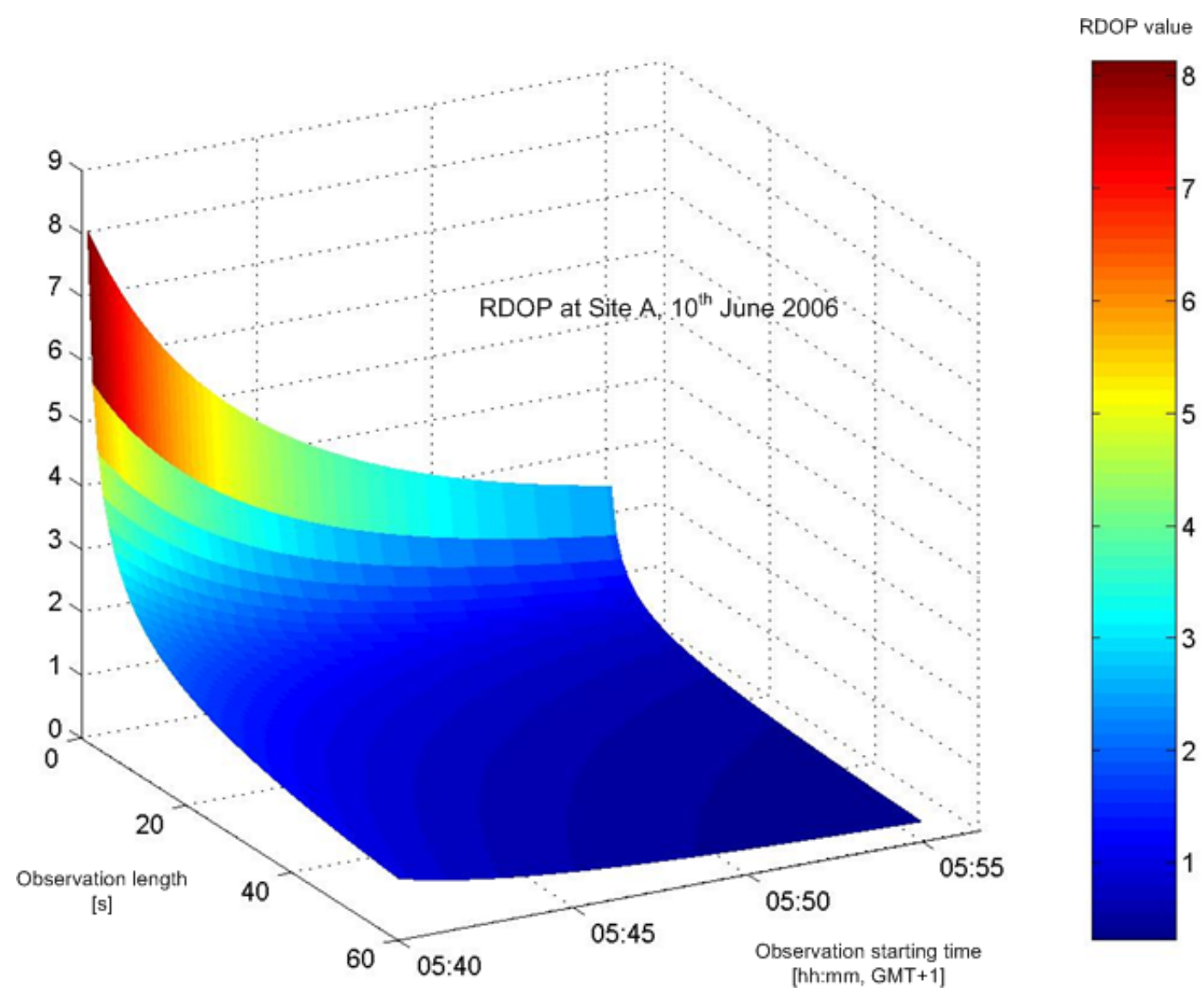

Figure 4: RDOP value modelling

The next step has led to computation of residuals $v$, using a weighted average, and deriving a value of the "general" standard deviation (for $n^{\prime}$ as number of degrees of freedom)

$$
s_{0}=\sqrt{\frac{\sum_{i=1}^{n} p_{i} v_{i}^{2}}{n^{\prime}}}
$$

Thus the standard deviation (used for estimation of RTK precision) can be expressed as

$$
\begin{aligned}
& s_{X}=s_{X_{0}} \sqrt{\frac{R M S_{i}^{2} H D O P_{i}^{2}}{2}} \\
& s_{Y}=s_{Y_{0}} \sqrt{\frac{R M S_{i}^{2} H D O P_{i}^{2}}{2}} \\
& s_{H}=s_{H_{0}} R M S_{i} \operatorname{VDOP}_{i}
\end{aligned}
$$

Three coordinates, $\mathrm{X}, \mathrm{Y}$ and $\mathrm{H}$, obtained in one observation epoch, are correlated. As the correlation relations between them are unknown, a precision estimation has been performed separately for each coordinate (Table 1).

Example (1): Considering values $\mathrm{RMS}=2,7 \mathrm{~mm}, \mathrm{HDOP}=1.26, \mathrm{VDOP}=1.93$ (mean values of all RMS and DOPs achieved during experiment performance), experimental outcome yields 
Table 1: Unit factors of coordinate standard deviations.

\begin{tabular}{lccc}
\hline \multicolumn{1}{c}{ Correction } & \multicolumn{3}{c}{ Coefficient } \\
Data source & $s_{Y_{0}}$ & $s_{X_{0}}$ & $s_{H_{0}}$ \\
\hline \hline RTK-FKP & 2.20 & 3.93 & 2.56 \\
RTK-PRS & 3.19 & 5.72 & 2.74 \\
RTK & 1.99 & 4.43 & 3.80 \\
\hline
\end{tabular}

the resulting standard deviations for RTK-FKP service as $s_{Y}=5.3 \mathrm{~mm}, s_{X}=9.5 \mathrm{~mm}$ and $s_{H}=13.3 \mathrm{~mm}$.

\section{Position change (accuracy estimation)}

As we are able to estimate precision of single point coordinates, we could estimate accuracy of distance computed from 3D-coordinates of two points. Thus we could derive single point position change with its accuracy and estimate a minimum position change, which we are able to determine with a certain level of risk.

Using (4), (5), and (6) and the error propagation law, we can derive the standard deviation of such point position change

$$
\begin{gathered}
\Delta=\sqrt{\left(X_{2}-X_{1}\right)^{2}+\left(Y_{2}-Y_{1}\right)^{2}+\left(H_{2}-H_{1}\right)^{2}}=\sqrt{\Delta_{X}^{2}+\Delta_{Y}^{2}+\Delta_{H}^{2}} \\
s_{\Delta}^{2}=\frac{1}{2 \Delta^{2}}\left[\left(R M S_{2}^{2} H D O P_{2}^{2}+R M S_{1}^{2} H D O P_{1}^{2}\right)\left(s_{X_{0}}^{2} \Delta_{X}^{2}+s_{Y_{0}}^{2} \Delta_{Y}^{2}\right)\right. \\
\left.+2 s_{H_{0}}^{2}\left(R M S_{2}^{2} V D O P_{2}^{2}+R M S_{1}^{2} V D O P_{1}^{2}\right) \Delta_{H}^{2}\right]
\end{gathered}
$$

Indexes 1 and 2 represent two different epochs of observation at one site. If we suggest a using significance level $\alpha=5$, we could derive the minimum detectable point displacement as:

$$
\Delta_{\min }=2 s_{\Delta}
$$

As we could see, its value is closely related to HDOP/VDOP and RMS values during observation in two epochs. This value depends on the direction of position change.

Example (2): Considering values RMS $=2.7 \mathrm{~mm}, \mathrm{HDOP}_{1}=\mathrm{HDOP}_{2}=1.26, \mathrm{VDOP}_{1}=\mathrm{VDOP}_{2}$ $=1.93$, Fig. 5 shows graph describing value $\Delta_{\min }$ in relation to azimuth and elevation of point position change for service RTK-FKP.

If we plot the surface built up by minimal detectable displacement vectors, we obtain a 3D analogy of 2D Helmert's curve. To simplify (8), we could split the displacement vector into two parts, describing displacement in the horizontal plane and the vertical direction. By introducing a mean standard deviation of coordinates in horizontal plane

$$
s_{X_{0}, Y_{0}}^{2}=\frac{1}{2}\left(s_{X_{0}}^{2}+s_{Y_{0}}^{2}\right)
$$

we are able to derive minimal detectable displacements in horizontal plane and vertical direction and have a better estimation of displacement precision in horizontal plane for different data sources of corrections from the CZEPOS

$$
\Delta_{\min , H_{z}}=s_{X_{0}, Y_{0}} \sqrt{R M S_{1}^{2} H D O P_{1}^{2}+R M S_{2}^{2} H D O P_{2}^{2}}
$$




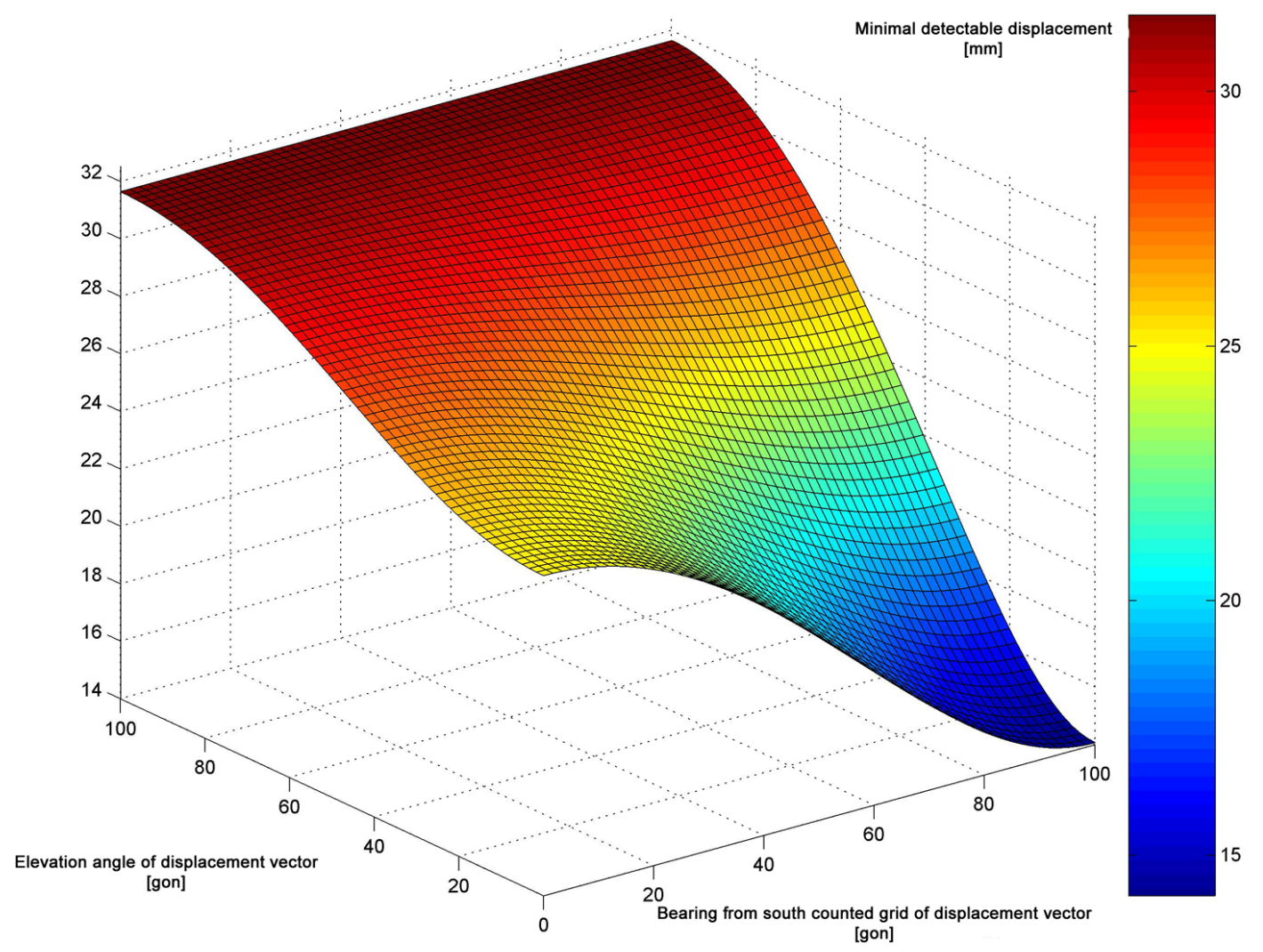

Figure 5: Minimal detectable displacement

Table 2: Unit factors of mean standard deviation in horizontal plane.

\begin{tabular}{lc}
\hline \multicolumn{1}{c}{ Correction } & $s_{X_{0}, Y_{0}}$ \\
\hline \multicolumn{1}{c}{ Data source } & \\
\hline RTK-FKP & 3.18 \\
RTK-PRS & 4.63 \\
RTK & 3.43 \\
\hline
\end{tabular}

Example (3): Considering values $\mathrm{RMS}=2.7 \mathrm{~mm}, \mathrm{HDOP}_{1}=\mathrm{HDOP}_{2}=1.26, \mathrm{VDOP}_{1}=\mathrm{VDOP}_{2}$ $=1.93$ and using RTK-FKP service, threshold for reliable displacement detecting would be $\Delta_{\min , H_{z}}=15 \mathrm{~mm}$ and $\Delta_{\text {min,height }}=38 \mathrm{~mm}$.

\section{Conclusions}

It is obvious that a permanent reference network holds great potential for different kinds of geodetic applications, requiring real-time data. The experiment shows some possibilities of land slide monitoring with GPS-RTK technology. Within a short observation time (seconds or a few minutes), it is possible to detect centimetre displacements in real time. This precision is more than sufficient for studying earth surface morphology and its changes [8] as well as for some applications of engineering surveying, such as displacement monitoring. Conclusions of the performed experiment has been used for pilot project of landslide monitoring, in clay 
quarry "Nepomyšl" [11]. However, as landslide slowed down, the need of higher monitoring precision, unachievable by GNSS/RTK emerged. Based on results of experiments it can be concluded that especially the service RTK-FKP (and its modern version RTK3) is suitable for application of GNSS technologies in the CZEPOS.

\section{Acknowledgements}

This contribution was published thanks to the financial support by Ministry of Education, Youth and Sports, the Czech Republic in the Research Program "Udržitelná výstavba" (Sustainable Construction), No. MSM 6840770005 financially supported by Ministry of Education, Youth and Sports, the Czech Republic.

\section{References}

[1] Jaroslav Braun and Pavel Hánek. "Geodetic monitoring methods of landslide-prone regions - application to Rabenov". In: AUC GEOGRAPHICA 49.1 (Sept. 2014), pp. 519. DOI: $10.14712 / 23361980.2014 .2$.

[2] Bernhard Hofmann-Wellenhof, Herbert Lichtenegger, and Elmar Wasle. GNSS - Global Navigation Satellite Systems: GPS, GLNASS, Galileo and more. Springer Vienna, 2008, p. 516. DOI: $10.1007 / 978-3-211-73017-1$.

[3] Jan Kostelecký and Miloš Cimbálník. "Převod souřadnic mezi ETRS-89 a S-JTSK pomocí globálního transformačního klíče (Transformation between ETRS-89 and SJTSK using Global Transformation Parameters)". In: Geodetický a kartografický obzor 53(95).12 (2007).

[4] Jan Kostelecký et al. "Quasigeoids for the Territory of the Czech Republic". In: Studia Geophysica et Geodaetica 48.3 (July 2004), pp. 503-518. DOI: 10.1023/b: sgeg . 0000037469.70838 .39$.

[5] Land Survey Office. CZEPOS website. http://czepos.cuzk.cz/.

[6] L. Manetti, M. Frapolli, and A. Knecht. "Permanent, autonomus monitoring of landslide movements with GPS". In: 1st Europen conference of landslides. Prague, Czech Republic. 2002, p. 6.

[7] Leoš Mervat and Miloš Cimbálník. Vyšší geodézie 2 (Advanced Geodesy 2), Czech Technical University in Prague. 178 pp. 1999.

[8] J. Pospíšil and M. Raška. "Geodetic methods in a study of earth surface processes". In: Geoscape Journal 1 (2006), pp. 13-20.

[9] M. Raška et al. "Using geodetic techniques for geomorphologic analyses of scree slopes in low-altitude forested regions and its implication for conservation management". In: Geographia Technica 2 (2011), pp. 87-100.

[10] G. Retscher. "Accuracy Performance of VRS Networks". In: Journal of Global Positioning Systems 1.1 (2002), pp. 40-47.

[11] K. Turčin. "Landslide monitoring in quarry "Nepomyšl"". Mining surveying documentation of Sedlecky kaolin a. s.. (in Czech, company restricted material, unpublished). 2004-2011. 
[12] R. Urban, M. Štroner, and K. Kovařík. "Comparison of GNSS measurement accuracy in reference stations network in territory of Prague". In: Geodetický a kartografický obzor 59(101).3 (2013), pp. 45-53.

[13] J. J. Westerveld. "Mobile Networks, Location Based Services lectures materials". TU Delft, Netherlands.

[14] G. Wübbena and A. Bagge. RTCM Message Type 59 - FKP for transmission FKP, version 1.1. Geo++ ${ }^{\circledR}$ GmbH IGS Workshop, Darmstadt, Germany. 8 pp. 2006.

[15] G. Wübbena, M. Schmitz, and A. Bagge. Real-Time GNSS Data Transmission Standard RTCM 3.0. Geo++ ${ }^{\circledR}$ GmbH IGS Workshop, Darmstadt, Germany. 26 pp. 2006.

[16] X. Yang and R. Brock. RDOP surface for GPS relative positioning. United States Patent No. 6057800. 2000. 